\title{
Age-Related Progression of Microvascular Dysfunction in Cystic Fibrosis: New Detection Ways and Clinical Outcomes
}

\author{
Marcela KRESLOVÁ ${ }^{1}$, Aneta SÝKOROVÁ ${ }^{1}$, Radka BITTENGLOVÁ ${ }^{2}$, Jan SCHWARZ ${ }^{1}$, \\ Renáta POMAHAČOVÁ ${ }^{1}$, Petr JEHLIČKA ${ }^{1}$, Jiří KOBR ${ }^{1}$, Ladislav TREFIL ${ }^{3}$, Josef \\ SÝKORA ${ }^{1}$
}

${ }^{1}$ Charles University in Prague, Faculty of Medicine in Pilsen, Faculty Hospital, Department of Pediatrics, Pilsen, Czech Republic, ${ }^{2}$ Charles University in Prague, Faculty of Medicine in Pilsen, Faculty Hospital, Department of Pneumology, Pilsen, Czech Republic, ${ }^{3}$ Charles University in Prague, Faculty of Medicine in Pilsen, Faculty Hospital, Department of Clinical Biochemistry and Hematology, Pilsen, Czech Republic

Received June 9, 2021

Accepted September 13, 2021

Epub Ahead of Print October 30, 2021

\begin{abstract}
Summary
There are concerns about altered vascular functions that could play an important role in the pathogenesis and influence the severity of chronic disease, however, increased cardiovascular risk in paediatric cystic fibrosis (CF) has not been yet fully understood. Aim was to analyze vascular disease risk and investigate changes over times in CF and controls. We prospectively enrolled $22 \mathrm{CF}$ subjects (a median age of 16.07 years), and 22 healthy demographically matched controls (a median age of 17.28 years) and determined endothelial function. We utilized a combined diagnostic approach by measuring the plethysmographic Reactive Hyperemia Index (RHI) as the post-to preocclusive endothelium-dependent changes of vascular tone, and biomarkers that are known to be related to endothelial dysfunction (ED): asymmetric dimethyl arginine (ADMA), high-sensitive CRP (hsCRP), VCAM-1 and E-selectin. $\mathrm{RHI}$ values were significantly lower in $\mathrm{CF}$ young adults $(p<0.005)$. HsCRP $(p<0.005)$, E-selectin $(p<0.001)$ and VCAM-1 $(p<0.001)$ were significantly increased in CF patients since childhood. The findings have provided a detailed account of the ongoing process of microvascular dysfunction with gradual progression with the age of CF patients, making them further at risk of advanced vascular disease. Elevations of biomarkers in CF children with not yet demonstrated RHI changes but with significantly reduced RHI in adulthood and lipid profile changes indicate the possible occurrence of ED with CF-related specific risk factors over time and will enable us to provide the best possible support.
\end{abstract}

Key words
Cystic fibrosis - Childhood • High-sensitive CRP • Endothelial dysfunction • Reactive hyperemia index

\section{Corresponding author}

Marcela Kreslová, Division of Pulmonology, Department of Paediatrics, Charles University in Prague, Faculty of Medicine in Pilsen, Faculty Hospital, Alej Svobody 80, Pilsen 304 60, Czech Republic. E-mail: kreslovam@fnplzen.cz

\section{Introduction}

Cystic fibrosis (CF) is a common, progressive, life-shortening chronic disease with multiple system involvement that usually begins in childhood and is incurable. Due to great advances in treatment goals and options in recent years, the quality and life expectancy of patients has continuously improved. However, there is still a need for additional medical applications focused on minimizing the severity of symptoms and complications in the treatment of $\mathrm{CF}$ which could constitute future therapies.

Involved in multiple risk factors of cardiovascular disease (CVD) are hypertension, dyslipidemia, diabetes, obesity, lack of physical activity, and gender-related differences in sex hormones (Kraml 2017, Kittnar et al 2020). Strong evidence suggests that systemic inflammation and autoimmune diseases contribute powerfully to this process (Ross 1999). Conversely, some data suggest that bilirubin has an anti- 
atherogenic effect (Vítek 2017).

Several studies on the prevalence of subclinical atherosclerosis in CF patients are currently available (Buehler et al. 2012, Poore et al. 2013, RodriguezMiguelez 2016, Tucker et al. 2019). However, a higher risk of CVD in CF has not been clearly recognized (Cross et al. 2013). Oxidative stress has been investigated in relation to endothelial dysfunction (ED) in $\mathrm{CF}$ in recent years by Olveira (Olveira et al. 2013) and Tucker (Tucker et al. 2019), playing an important role in the pathogenesis of lung impairment in CF patients at an early age (Hector et al. 2014, Kettle et al. 2014). Pancreatic insufficiency has also been associated with an imbalance of oxidants and antioxidants. Collectively, several studies support that airway colonization might interfere with microvascular function. The importance of the relationship between colonization, systemic inflammatory response and oxidative stress with gradual development into ED was reported by Reverri et al. (2014) who showed a possible development of ED in patients with $\mathrm{CF}$ from localized inflammatory airway process to systemic vascular dysfunction. Subsequently, consideration of CFTR dysregulation may shed light on consequent impairment of mucociliary clearance leading to airway colonization. The authors reported that the progression of $\mathrm{CF}$ is responsible for chronic airway infection and especially acute exacerbation of $\mathrm{CF}$ with activation of inflammatory immune processes, in which there is a massive infiltration of polymorphonuclear neutrophils into the airways, followed by overproduction of proinflammatory cytokines, reactive oxygen species and nitrogen (Reverri et al. 2014).

With prolonged life expectancy of CF patients, $\mathrm{CF}$ can be expected to be co-morbid in adults, compounded by a chronic systemic inflammatory process in a combination with a prothrombotic state and oxidative stress. What causes the risk of CVD in CF is not fully understood. One possible explanation could be a number of major pro-atherogenic CVD risk factors in $\mathrm{CF}$ adults (Reverri et al. 2014) including systemic inflammatory process and oxidative stress. The oxidative stress is the main pathophysiologic mechanism leading to impaired nitric oxide bioavailability and to $\mathrm{ED}$, as the vascular endothelium is a major target for oxidative stress, prothrombogenic factors, dyslipidemia, high fat intake, low physical activity and CF-linked diabetes. To our knowledge, however, there is not enough published pediatric data on the preclinical stage of atherosclerosis and CVD in CF, so most conclusions regarding CVD have so far been based on cohort observations for adults only (Poore et al. 2013, Rodriguez-Miguelez 2016, Cross et al. 2013, Reverri et al. 2014, Hull et al. 2009).

ED is a well-established systemic disorder that represents an early marker of CVD and precedes the development of atherosclerosis (Vrablík 2017). Most commonly, the impaired endothelium-dependent vasodilatation is defined as a hallmark of ED (Widlansky et al. 2003, Donato et al. 2018). In the earliest stages, it is a merely functional damage of the endothelial lining due to mechanical, physicochemical and immunological factors. ED is characterized by a reduced vasodilatory response to a suitable ischemic stimulus as well as a procoagulant and proinflammatory state becoming a proatherosclerotic structure (Hamburg et al. 2008). The reversibility of ED may be a primary target in the effort to optimize therapeutic strategies and to decrease CVD risk in CF. Early detection of ED may have therapeutic and prognostic implications (Widlansky et al. 2003, Slíva et al. 2019). Unfortunately, ED in childhood has received a little attention from researchers, and studies on ED in comparable pediatric CF populations are lacking. Thus, knowledge of ED in this disease is indispensable for diagnostic and therapeutic strategies. Consequently, there is a need for novel non-invasive diagnostic tools for the detection of ED (Bonneti et al. 2003).

Therefore, the primary objective of the study was to determine (a) whether there is a significant difference in the reactive hyperemia index (RHI) in CF patients compared to healthy controls (HC) already in childhood, and (b) whether there is a correlation between RHI and specific biomarkers. We hypothesize that a combination of RHI and biomarkers could be used to detect $\mathrm{ED}$ in children and young adults with $\mathrm{CF}$.

\section{Methods}

\section{Study design and data source}

This prospective observational cohort study was conducted at the CF unit at our tertiary referral center (the Department of Pediatrics and Pediatric Pulmonology, Charles University in Prague, Faculty Hospital Pilsen). A total of 22 patients with CF were enrolled in the study regardless of airway colonization, nutritional status and lung function. Diagnosis CF was confirmed by a positive sweat test and molecular genetic testing. All CF subjects were treated symptomatically according to valid standards of the European Society for CF (Castellani et al. 2018). The median age of patients was 16.07 years 
vs 17.28 years in HC. All CF subjects had undergone a standard cardiology examination and had normal both systolic and diastolic heart function throughout the follow-up. None had known vascular disease.

The control group consisted of 22 healthy subjects with no clinical signs of CF, without a history of heart, inflammatory, metabolic, neoplastic or peripheral vascular disease and without antibiotic, antiinflammatory, and vasoactive medications affecting endothelial function, or any chronic disease known to affect microvascular function. Exclusion criteria for both groups were dyslipidemia, obesity, smoking, positive family history of premature cardiovascular events, abnormal left-ventricular function.

\section{Reactive hyperemia index measurements}

Non-invasive measurement of RHI is based on the principle of plethysmographic evaluation of the postocclusive endothelium-dependent changes in peripheral arterial tone (PAT) using an EndoPAT2000 recorder (Itamar Caesarea ${ }^{\circledR}$, Israel). Initially, body mass index and blood pressure in the non-dominant arm were measured. During the first phase in the supping position in the temperature-controlled room with uniform biosensors located on the fingertips, the PAT input values were recorded on upper limbs. This was followed by a five-minute occlusion of the brachial artery on the non-dominant limb with a pressure cuff inflated $60 \mathrm{~mm} \mathrm{Hg}$ above the systolic pressure, at least $200 \mathrm{~mm}$ $\mathrm{Hg}$. The post-occlusive endothelium-induced dilation with reactive hyperemia was captured as an increase of the PAT signal amplitude. The EndoPAT index (RHI) is calculated automatically from the ratio of the occlusive and pre-occlusive arterial flow (PAT) relative to the values of the simultaneously measured, non-closed contralateral limbs. Insufficient increase in PAT amplitude during the third post-occlusive phase is associated with ED (Fig. 1). The RHI cut-off is set to 1.67 in adults. According to literature data, the average RHI in healthy adults is 2.06 (Domsic et al. 2014).

\section{Laboratory measurements}

We evaluated biochemical parameters related to ED to determine the subclinical stage of atherosclerosis. After overnight fasting, blood samples were obtained from all the subjects in a standard clinical setting. All tests were performed in a blinded fashion. We included asymmetric dimethylarginine (ADMA) as a competitive NO-synthase inhibitor, E-selectin and VCAM-1 vascular cells adhesive molecules, all measured by Elisa method (OLD Diagnostica ${ }^{\circledR}$, BioVendor ${ }^{\circledR}$ ), as well as high sensitive C-reactive protein (hsCRP) measured by a particle-enhanced immuno-turbidimetric assay technique (Orion Diagnostica ${ }^{\circledR}$ ). In relation to ED, we evaluated the plasma lipid panel in all subjects. Serum levels of total cholesterol, triglycerides, HDL and LDL were determined in a clinical laboratory using an autoanalyzer (GTP Human ${ }^{\circledR}$ and CHOD-PAP Dialab ${ }^{\circledR}$ ).

\section{Statistics}

The statistical analysis was performed using SAS software (SAS Institute Inc., Cary ${ }^{\circledR}, \mathrm{NC}$, USA). Values obtained from individual measurements were expressed using descriptive statistics. Statistical differences were calculated using a non-parametric Wilcoxon two-sample test or its generalized variant of the Kruskal-Wallis test. Correlations among RHI and biochemical parameters were assessed using Spearman's and Kendall's rank correlation. For all analyses, a p-value of 0.05 or less was accepted as being statistically significant.
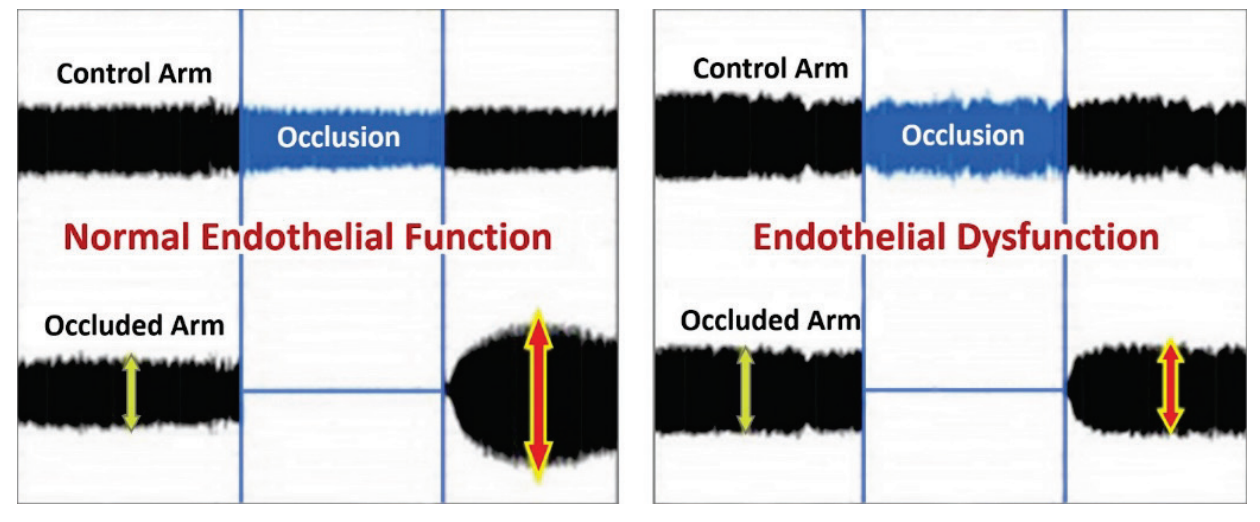

Fig. 1. RHI measurement. Comparison of healthy controls curves with normal endothelial function and CF patients with endothelial dysfunction. Upper curve with PAT amplitude recorded on control arm. Lower curve with PAT amplitude recorded on the examined arm with occlusion during the second phase and subsequent reactive hyperemia during the third phase of the examination. https://level1diagnostics.com/te sting/ 
Ethics

Our study was conducted in accordance with the principles of the Declaration of Helsinki. The local Ethics Committee approved the study protocol (No. 438/2015). An informed consent was obtained from each patient or their parents.

\section{Results}

\section{Demographics of the study sample}

During the study period, a total of 44 consecutive subjects were eligible for inclusion. For an overview of the baseline demographic and clinical characteristics of $\mathrm{CF}$ patients and $\mathrm{HC}$, see Table 1. No significant differences were observed between groups in terms of age, gender ratio, ethnicity or BMI. Eligible study participants were Czech nationality (Caucasian). $27.3 \%$ of CF patients were treated for chronic Pseudomonas aeruginosa infection, others had intermittent or chronic Staphylococcus aureus infection.
$36.4 \%$ of patients were F508del homozygous and $50 \%$ were heterozygous for F508del mutation. $27.3 \%$ of patients were treated for hepatic complications of CF, $22.7 \%$ of patients had impaired glucose tolerance or already treated CF-associated diabetes mellitus. Pulmonary function was normal in $68.2 \%$ of patients. Poor nutritional status has not been demonstrated in CF subjects.

\section{RHI and biochemical parameters}

There was no significant difference in RHI between $\mathrm{CF}$ and $\mathrm{HC}$ up to 18 years of age, however in the group of patients over 15 years (adolescents and young adults), there was a significant correlation of RHI with age $\quad(\mathrm{r}=-0.60, \quad \mathrm{p}<0.05)$. A statistically significant difference was confirmed in the age group 15-18 years compared to over 18 years $(1.80$ vs $1.34 ; \mathrm{p}<0.05)$, as shown in Fig. 2. The dynamics of RHI with age is also demonstrated by the RHI result in young CF adults (1.34 vs 2.19; $<<0.05)$, as shown in Fig. 3 .

Table 1. Demographic data

\begin{tabular}{|c|c|c|c|c|}
\hline Data & $\begin{array}{c}\text { CF } \\
\text { median } \\
\text { (min; max) }\end{array}$ & $\begin{array}{c}\text { Controls } \\
\text { median (min; max) }\end{array}$ & p-value & $\begin{array}{c}\text { Statistical } \\
\text { Significance }\end{array}$ \\
\hline Number & 22 & 22 & & \\
\hline Gender (male/female) & $6 / 16$ & $5 / 17$ & 0.025 & equivalency \\
\hline $\operatorname{Age}(y)$ & $16.07(10.68 ; 35.58)$ & $17.28(12.64 ; 25.40)$ & 0.006 & $\begin{array}{l}\text { equivalency } \\
\qquad( \pm 5)\end{array}$ \\
\hline$B M I\left(k g / m^{2}\right)$ & $19.25(14.84 ; 27.20)$ & $20.52(16.72 ; 27.16)$ & 0.3 & NS \\
\hline Systolic blood pressure ( $\mathrm{mmHg}$ ) & $111(90 ; 136)$ & $116(104 ; 135)$ & 0.09 & NS \\
\hline $\begin{array}{l}\text { Diastolic blood pressure } \\
\text { (mmHg) }\end{array}$ & $60(50 ; 86)$ & $69(55 ; 88)$ & 0.13 & NS \\
\hline Total cholesterol (mmol/l) & $3.26(2.40 ; 4.70)$ & $4.41(2.10 ; 6.06)$ & 0.002 & $\mathrm{p}<0.005$ \\
\hline LDL cholesterol (mmol/l) & $1.78(1.09 ; 3.01)$ & $2.42(1.14 ; 3.63)$ & 0.01 & $\mathrm{p}<0.01$ \\
\hline HDL cholesterol (mmol/l) & $1.15(0.75 ; 1.81)$ & $1.60(1.14 ; 2.20)$ & 0.0003 & $\mathrm{p}<0.001$ \\
\hline$T G(\mathrm{mmol} / \mathrm{l})$ & $1.00(0.54 ; 1.72)$ & $0.85(0.57 ; 1.36)$ & 0.17 & NS \\
\hline
\end{tabular}

Values are expressed as the median with minimum and maximum values in parentheses; CF - cystic fibrosis; BMI - body mass index; HDL - high density lipoprotein cholesterol; LDL - low density lipoprotein cholesterol; TG - triglycerides; NS - non-significant

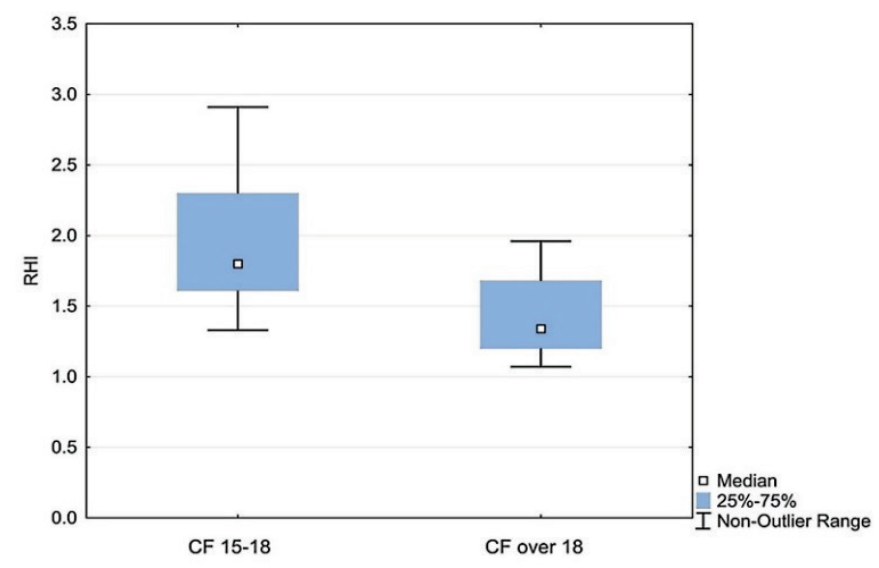

Fig. 2. $\mathrm{RHI}$ in $\mathrm{CF}$ children $15-18$ years vs CF adults. Boxes indicate the inter-quartile range. Horizontal lines within boxes indicate medians. Whiskers extend to the highest or lowest values; RHI - reactive hyperemic index; CF - cystic fibrosis 


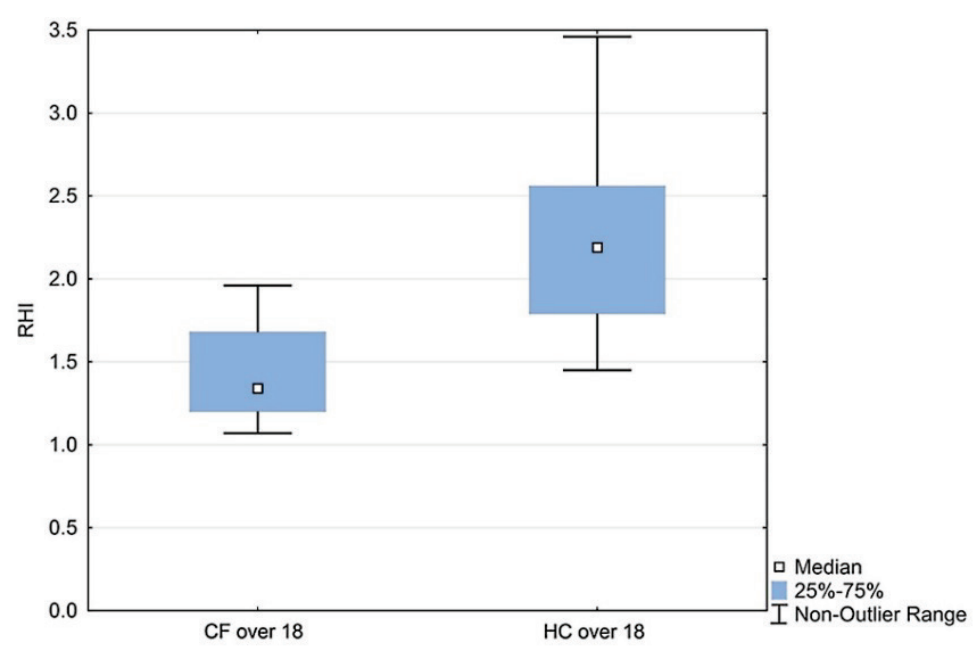

Fig. 3. RHI in CF adults vs HC. Boxes indicate the inter-quartile range. Horizontal lines within boxes indicate medians. Whiskers extend to the highest or lowest values; RHI - reactive hyperemic index; CF cystic fibrosis; HC - healthy controls

Table 2. RHI and biomarker values.

\begin{tabular}{|c|c|c|c|c|}
\hline Data & $\begin{array}{c}\text { CF } \\
\text { median (min; max) }\end{array}$ & $\begin{array}{c}\text { Controls } \\
\text { median (min; max) }\end{array}$ & p-value & $\begin{array}{c}\text { Statistical } \\
\text { Significance }\end{array}$ \\
\hline RHI & $1.38(1.07 ; 2.91)$ & $1.81(1.40 ; 3.46)$ & 0.003 & $\mathrm{p}<0.005$ \\
\hline $\begin{array}{l}h s C R P \\
(m g / l)\end{array}$ & $2.04(0.03 ; 35.00)$ & $0.31(0.02 ; 1.64)$ & 0.002 & $\mathrm{p}<0.005$ \\
\hline $\begin{array}{l}V C A M-1 \\
(\mu g / l)\end{array}$ & $1112.00(849.00 ; 1669.00)$ & $939.95(556.00 ; 1137.50)$ & 0.001 & $\mathrm{p}<0.001$ \\
\hline $\begin{array}{l}\text { E-selectin } \\
(\mu g / l)\end{array}$ & $98.50(36.10 ; 179.70)$ & $46.10(20.80 ; 106.10)$ & 0.0002 & $\mathrm{p}<0.001$ \\
\hline $\begin{array}{l}\text { ADMA } \\
(\mu \mathrm{mol} / \mathrm{l})\end{array}$ & $0.47(0.27 ; 0.65)$ & $0.56(0.31 ; 0.73)$ & 0.07 & NS \\
\hline
\end{tabular}

Values are expressed as the median with minimum and maximum values in parentheses; RHI - reactive hyperemic index; hsCRP - high sensitive C-reactive protein; VCAM-1 - vascular cell adhesive molecule; ADMA - asymmetric dimethylarginine; NS - non-significant

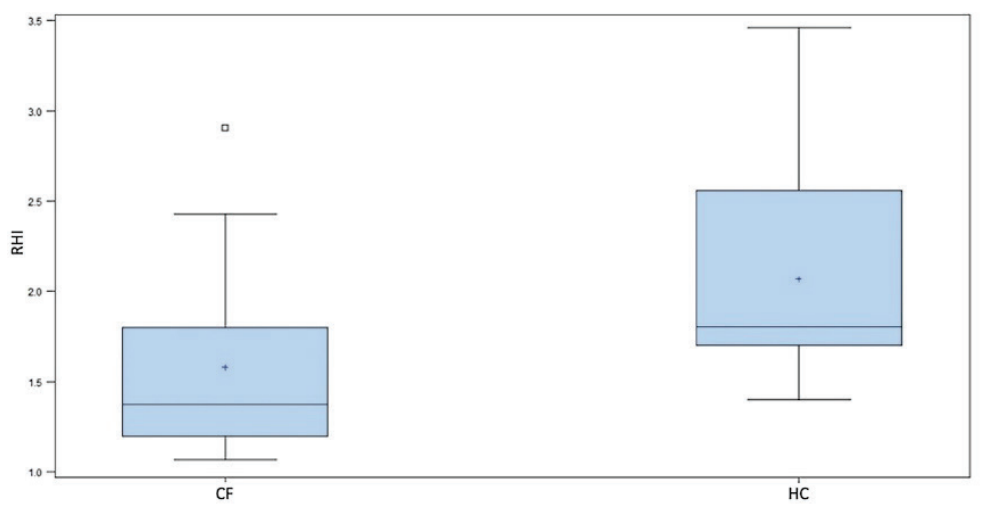

Fig. 4. RHI in CF children and adults vs HC. Boxes indicate the inter-quartile range. Horizontal lines within boxes indicate medians. Whiskers extend to the highest or lowest values; RHI - reactive hyperemic index; CF - cystic fibrosis; HC - healthy controls

Nutritional status did not correlate with RHI, but a moderate negative correlation was found with VCAM-1 $(\mathrm{r}=-0.565 ; \mathrm{p}<0.05)$. A strong negative correlation of RHI with ADMA was found $(\mathrm{r}=-0.694 ; \mathrm{p}<0.01)$. We showed a moderately positive correlation of RHI with hsCRP $(\mathrm{r}=0.592 ; \mathrm{p}<0.05)$ and a moderately negative correlation of RHI with E-selectin $(\mathrm{r}=-0.541 ; \mathrm{p}<0.05)$. No correlations were found between RHI and biomarkers in CF patients in relation to genetic mutations, airway colonization, pulmonary function, and complications of $\mathrm{CF}$. In the HC group under 18 years of age, no correlation was found between RHI and biomarkers. 
Plasma hsCRP levels were significantly higher in $\mathrm{CF}$ children $(\mathrm{p}<0.01)$ as well as in $\mathrm{CF}$ adults $(\mathrm{p}<0.005)$ compared to HC. Plasma VCAM-1 levels were significantly higher in $\mathrm{CF}$ children $(\mathrm{p}<0.01)$ and in $\mathrm{CF}$ adults $(\mathrm{p}<0.001)$. E-selectin levels in $\mathrm{CF}$ children were significantly higher compared to $\mathrm{HC}(\mathrm{p}<0.05)$ as well as in CF adults $(p<0.001)$. No significant difference in ADMA levels was observed between CF patients and the HC. The results of the determined biomarkers in the total CF group are summarized in Table 2. RHI was statistically significantly lower in the overall $\mathrm{CF}$ patient group compared to $\mathrm{HC}(1.38$ vs $1.81 ; \mathrm{p}<0.005)$. The results are shown in Fig. 4. A statistically significant difference $(\mathrm{p}<0.05)$ with a specificity of $77.27 \%$ and a sensitivity of $63.64 \%$ was found at the RHI cut-off point 1.67.

Total cholesterol, high-density lipoproteins (HDL) and low-density lipoproteins (LDL) levels were significantly lower in CF patients (cholesterol: $\mathrm{p}<0.005$, LDL: $p<0.01$, HDL: $p<0.001$ ). Triacylglycerol levels were not statistically significant between groups. In CF patients, nutritional status did not correlate with RHI. A moderate negative correlation of BMI with VCAM-1 was demonstrated $(\mathrm{r}=-0.601 ; \mathrm{p}<0.005)$. In $\mathrm{CF}$ patients, a slightly negative correlation of RHI with E-selectin was found $(r=-0.472 ; p<0.05)$. A slightly negative correlation between RHI and ADMA was confirmed in $\mathrm{HC}$ $(\mathrm{r}=-0.471, \mathrm{p}<0.05)$.

\section{Discussion}

CVD in CF patients are usually attributed to the secondary effects of progressive pulmonary disease. With the introduction of CFTR modulator therapy into practice, a further improvement in the quality of life and prolonged life expectancy can be expected, and thus an increase in the prevalence of vascular diseases. Due to the localization of CFTR in the vascular endothelium and smooth muscle, CFTR dysfunction can directly affect cardiovascular function (Poore et al. 2021).

To the best of our knowledge, this is the first published report on ED in children and young adults with CF using a combined diagnostic approach by assessing RHI by endoPAT ${ }^{\circledR}$ plethysmography and specific biochemical parameters to assess the dynamics of changes of ED with age. In our study, we have shown that the patients with $\mathrm{CF}$ are at the risk of progression to CVD. The results can be summarized in three main findings. First, we found significantly different ED values in $\mathrm{CF}$ patients compared to the normal response in $\mathrm{HC}$ and significant correlations with biochemical markers. Second, these findings of an attenuated, post-occlusion hyperemic microvascular response may imply a possible association with premature ED in young CF adults confirming the progressive development of vascular dysfunction since childhood, making them further at risk of advanced vascular disease. Third, there is an ample evidence to suggest that the differences in $\mathrm{ED}$, as seen in our targeted group of children, implicate some pathophysiological mechanisms responsible for the progression of CVD in CF over time. We suggest that these findings may facilitate efficient resource utilization and direct appropriate care to high-risk CF patients.

Considering the relationship between ED and atherosclerosis, it is likely that the status of an individual endothelial function may reflect the propensity to develop atherosclerotic disease and thus may serve as a marker of an unfavorable cardiovascular prognosis (Hadi et al. 2005). In most patients with CF, there are no symptoms of CVD complications. This makes the need for introducing minimally invasive measures which would allow early detection of ED, however, early detection of microvascular dysfunction seems to be particularly difficult. Attempts to detect vascular disease early are associated with evidence of morphological changes as early as childhood (Morrison et al. 2010), when the clinical course is still quite inconspicuous and reversible. A few published studies in the literature have reported a link between chronic inflammatory diseases activating systemic inflammatory biomarkers and increased incidence of CVD (Domsic et al. 2014, Jehlička et al. 2014, Čejková et al. 2017, Masopustová et al. 2018a).

The glycocalyx/endothelial surface layer (ESL), coating the luminal surface of vascular endothelium is the main regulator of vascular wall homeostasis and contributes to a variety of pathologies (Yamaoka-Tojo et al. 2020, Nieuwdorp et al. 2005). ESL derangement plays an important role in the formation of ED (Yilmaz et al 2019), leading to NO dysregulation, excessive reactive oxygen species (ROS), cytokine elaboration, loss of coagulation control, and an increase in platelet and leucocyte adhesion, which impair the capacity of the vascular endothelium to perform its many functions. ESL damage is triggered by inflammatory processes through the activation of specific enzymes (matrix metalloproteinases, heparanase, and hyaluronidase) which are mainly activated by proinflammatory factors such as ROS and cytokines (TNF- $\alpha$ and IL-1 $\beta$ ) (Masola 
et al. 2021, Yilmaz et al 2019, Becker et al 2015). The findings of the study performed by Johansson (Johansson et al. 2011) are also impressive; they reported that a high syndecan-1 level, as a circulating component of ESL degradation, is associated with inflammation, protein $\mathrm{C}$ depletion, and fibrinolysis and levels of syndecan-1 might correlate with E-selectin.

A study of Poore et al. (2013) investigated ED in young fairly healthy CF patients with a four-fold higher hsCRP level, detected ED sonographically by the FlowMediated Dilation (FMD) method as well as confirmed that ED is related to pulmonary function and exercise capacity. Fox et al. (2013) declared the effects of restoring endothelial function by oral using of an antioxidant cocktail of vitamins C, E and alpha-lipoic acid by assessment brachial artery FMD in young $\mathrm{CF}$ patients. Hull et al. demonstrated increased augmentation index (AI), as a parameter of ED, expressed of artery vascular stiffness relating to both age and atherosclerotic processes (Hull et al. 2009). Hull et al. (2013) also measured AI in CF patients and confirmed the significant reductions in vascular stiffness due to antibiotic treatment.

There are relevant methods for assessing ED, most notably being Sidestream Dark Field imaging (SDF) as well as the orthogonal polarization spectral (OPS) imaging, photoacoustic imaging (PAI) and optical coherence tomography (OCT) (Goedhart et al. 2007, Nieuwdorp et al. 2005, Hashimoto et al. 2018), each with distinct advantages and disadvantages. From the SDF images of vessels, some physical quantities such as vessel length, sharpness, vessel diameter, and velocity of red blood cells (RBCs) can be estimated (Dobbe et al. 2008). Oxygen supplies insufficient in microcirculation may lead to tissue hypoxia which is considered to be one of the factors of serious diseases, such as CF and chronic bronchitis (Airley et al. 2000). Hashimoto et al. (2018) confirmed that SDF oximetry can observe oxygen saturation $\left(\mathrm{SO}_{2}\right)$ changes that occur in accordance with alteration of the microcirculation and is effective for understanding disease dynamics. Other studies have dealt with the evaluation of vascular changes in CF (Buehler et al. 2012, Henno et al. 2009).

Biomarker hsCRP is associated with an atherogenic process and its elevated levels are a predictive factor of morbidity and mortality in cardiovascular events and in apparently healthy individuals, regardless of commonly known risk factors (Morrison et al. 2010). Looking at the results of our research, we demonstrated significantly increased levels of hsCRP in CF patients since childhood, as a sign of endothelial pro-inflammatory activity associated with a chronic systemic inflammatory process (Masopustová et al. 2018b), consistent with our previously reported data in children with Crohn's disease (Jehlička et al. 2014) and acute lymphoblastic leukemia (Masopustová et al. 2018a).

Higher levels of vasoadhesive molecules (VCAM-1) and E-selectin are an expression of endothelial activation in $\mathrm{CF}$ patients. Nowak demonstrated higher VCAM-1 levels in CF patients (Nowak et al. 2017) as opposed to De Rose (De Rose et al. 1998).

Current evidence suggests that a higher level of ADMA is an indication of ED and may be a potential causal factor for ED in $\mathrm{CF}$, as the synthesis of nitric oxide triggering vasodilation is impaired. However, we did not find a significant change of this biomarker in CF patients. We did not expect these results, as we assumed that the role of ADMA is often highlighted in the pathogenesis of microvascular changes. These findings suggest that the importance of this biomarker for ED detection could be reduced and the advantage of a combined measurements has been increased. Based on these findings, it seems obvious that to assess microvascular function in $\mathrm{CF}$, stronger emphasis should be put on the combined diagnostic approach. These data underline the need of caution when using single ADMA values as markers of ED.

In the present study, we demonstrated significant lipoprotein abnormalities that may be caused by peroxidative stress due to chronic progressive noninfectious inflammation in CF. Lower HDL levels are considered a significant risk factor for atherogenesis in CF confirming conclusions in previously published studies (Poore et al. 2013, Cross et al. 2013).

To date, no previous studies have evaluated the relationship between $\mathrm{ED}$ and the increasing age in $\mathrm{CF}$. In addition, the study subjects have been children and young adults, and the findings variable. One of the most important outcomes of the present research is the gradual development of RHI with age of young CF patients. In the present study, with increasing age, patients with $\mathrm{CF}$ developed the changes of microvascular function over time. There was no statistically significant difference in RHI compared to $\mathrm{HC}$ in pediatric $\mathrm{CF}$ patients. On the contrary, we observed the above-mentioned changes in young adults with $\mathrm{CF}$. We revealed statistically 
significant differences in RHI compared to HC. In the group of patients over 15 years of age, we demonstrated a statistically significant correlation of RHI with age. Comparison of RHI in the group of 15-18 years with the group of patients over 18 years showed a statistically significant difference in RHI values (median 1.80 vs 1.34) with substantial tendency to decrease RHI in adulthood to pathological values, confirming our hypothesis about the effect of chronic inflammatory, age-progressing process on microvascular function. To address this issue, the results of our study confirmed the ongoing process of CVD with gradual progression with age, while confirming the worsening of ED in CF adults compared to adolescents. An increase in three biochemical markers in CF patients as early as childhood with as yet unchanged RHI but with significantly reduced RHI in adulthood and changes in lipid metabolism indicate the possible occurrence of ED with specific risk factors in $\mathrm{CF}$ patients and gradual progression of endothelial changes with age.

We suggest that the progression of ED is related to the intensity and duration of risk factors in CF. The method of non-invasive determination of ED by combination of RHI measurements and determination of specific biomarkers could become a suitable method enabling the early detection of cardiovascular risk in all CF patients with regard to the severity of the disease, limited therapy options and often therapeutically difficult to affect disease progression.

\section{Strengths and limitations}

The most remarkable strength of the present study is a search strategy to minimize the potential for bias, detailed, prospectively collected data, evaluating the dynamics of change with age and a combined approach. Controls were recruited in the same period from the same community, thereby avoiding problems of bias resulting from inappropriate controls. All patients were treated in a single central unit and followed up in a uniform manner. Moreover, the study is strengthened by the use of validated automatic RHI analysis which substantially reduces a human factor. Simultaneous measurement of the contralateral non-occluded arm allows the elimination of unintended exogenous changes during examination. The close relationship between decreased RHI and coronary dysfunction was confirmed by several invasive methods (Selamet Tierney et al. 2009). Czech children and young adults with $\mathrm{CF}$ represent clinical and ethnic homogeneity that is a clear advantage in such studies.
However, the following limitations need to be discussed. Limitation is a smaller sample size compared to adult studies. However, this is the case with most previous comparable studies in children. As described elsewhere, strengths and limitations of an absence of a precise cut-off limit for RHI in children and uniform sensors with no definition of the minimum finger thickness (Hamburg et al. 2008, Selamet Tierney et al. 2009, Kelly et al. 2014) have already been extensively discussed. Although there is an imminent danger of overinterpretation of findings in observational studies, our results offer new insight into the vascular disease of CF patients. To avoid inaccurate results caused by measuring younger children with fingers too small for sensors, we selected participants of age 10.5 and higher. Kelly demonstrated that younger age is associated with lower RHI but not lower FMD among adolescents and results of their study suggest that age is associated with RHI (Kelly et al. 2014). Therefore, we selected the control group with age comparable to CF patients. Hamburg demonstrated an increased baseline pulse amplitude (PAT) in obese persons with metabolic syndrome and an inverse relationship between baseline and response PAT to hyperemia (Hamburg et al. 2008). Some studies have not found a correlation between FMD and RHI with respect to ED (Allan et al. 2013) which may be explained by different properties of large conductive brachial arteries and the peripheral resistive artery bed.

Although we have to take a cautious approach when interpreting these findings, we believe our data is relevant as it reflects the correlations with the observed parameters and covers significant differences between the groups, and several potential limitations did not compromise our extrapolations related to the risk of vascular disease in this high-risk population.

\section{Conclusions}

Our study is the first to assess CVD risk in patients with $\mathrm{CF}$ in childhood and young adulthood using a combined diagnostic approach of plethysmographic RHI and biochemical markers. Significantly attenuated RHI, elevated plasma levels of hsCRP, VCAM-1 and E-selectin support a hypothesis of increased risk of premature ED in CF patients. Of note, the risk of CVD in CF patients has been significantly increasing with the age. These data provide evidence that vascular ED occurs in a high-risk cohort of young patients with $\mathrm{CF}$, and the 
combined approach seems to be a promising method for the assessment of microvascular dysfunction. As the measures of ED become clinically applicable, we suggest that all subjects deserve a great attention in the effort to lower the risk of CVD for the majority of pediatric highrisk CF patients. It is conceivable that comprehensive diagnostic assessments allowing early identification, targeted management and therapeutic correction of ED may lead to improved prognosis in high-risk CF patients. We suggest that the current approaches are important avenues for future research and may have far-reaching clinical implications. These studies might help to develop unique therapeutic targets and management strategies for control of CVD and can lead to sustained improvements in $\mathrm{ED}$ in the high- risks patients with $\mathrm{CF}$.

\section{Conflict of Interest}

There is no conflict of interest.

\section{Acknowledgements}

This study was supported by research grant PROGRES Q39.

\section{References}

ALLAN RB, DELANEY CL, MILLER MD, SPARK JI: A comparison of flow-mediated dilatation and peripheral artery tonometry for measurment of endothelial function in healthy individuals and patients with peripheral artrial disease. Eur J Vasc Endovasc Surg 45: 263-269, 2013. https://doi.org/10.1016/j.ejvs.2012.12.002

AIRLEY RE, MONAGHAN JE, STRATFORD IJ: Hypoxia and disease: opportunities for novel diagnostic and therapeutic prodrug strategies. Pharm J 264: 666-673, 2000.

BECKER BF, JACOB M, LEIPERT S, SALMON AH, CHAPPELL D: Degradation of the endothelial glycocalyx in clinical settings: searching for the sheddases. $\mathrm{Br} \mathrm{J}$ Clin Pharmacol 80: 389-402, 2015. https://doi.org/10.1111/bcp.12629

BONNETI PO, LERMAN LO, LERMAN A: Endothelial dysfunction - A marker of Atherosclerotic Risk. Arterioscler Thromb Vasc Bio 23: 168-175, 2003. https://doi.org/10.1161/01.ATV.0000051384.43104.FC

BUEHLER T, STEINMANN M, SINGER F, REGAMEY N, CASAULTA C, SCHOENI MH, SIMONETTI GD: Increased arterial stiffness in children with cystic fibrosis. Eur Respir J 39: 1536-1537, 2012. https://doi.org/10.1183/09031936.00212511

CASTELLANI C, DUFF AJA, BELL SC, HEIJERMAN HGM, MUNCK A, RATJEN F, SERMET-GAUDELUS I, SOUTHERN KW, BARBEN J, FLUME PA, HODKOVÁ P, KASHIRSKAYA N, KIRSZENBAUM MN, MADGE S, OXLEY H, PLANT B, SCHWARZENBERG SJ, SMYTH AR, TACCETTI G, WAGNER TOF, WOLFE SP, DREVINEK P: ECFS best practice guidelines: the 2018 revision. J Cyst Fibros 17: 153-178, 2018. https://doi.org/10.1016/j.jcf.2018.02.006

CROSS CE, REVERRI EJ, MORRISSEY BM: Joining the crowd: cystic fibrosis and cardiovascular disease risk factors. Chest 143: 882-884, 2013. https://doi.org/10.1378/chest.12-2444

ČEJKOVÁ S, KRÁLOVÁ LESNÁ I, FRONĚK J, JANOUŠK L, KRÁLOVÁ A, ŽDYCHOVÁ J, POLEDNE R: Pro-inflammatory gene expression in adipose tissue of patients with atherosclerosis. Physiol Res 66: 633-640, 2017. https://doi.org/10.33549/physiolres.933352

De ROSE V, OLIVA A, MESSORE B, GROSSO B, MOLLAR C, POZZI E: Circulating adhesion molecules in cystic fibrosis. Am J Respir Crit Care Med 157: 1234-1239, 1998. https://doi.org/10.1164/ajrccm.157.4.9704134

DOBBE JGG, STREEKSTRA GJ, ATASEVER B, VAN ZIJDERVELD R, INCE C: Measurement of functional microcirculatory geometry and velocity distributions using automated image analysis. Med Biol Eng Comput 46: 659-670, 2008. https://doi.org/10.1007/s11517-008-0349-4

DOMSIC RT, DEZFULIAN C, SHOUSHTARI A, IVANCO D, KENNY E, KWOH CK, MEDSGER TA, CHAMPION HC: Endothelial dysfunction is present only in the microvasculature and microcirculation of early diffuse systemic sclerosis patients. Clin Exp Rheumatol 32: 154-160, 2014.

DONATO AJ, MACHIN DR, LESNIEWSKI LA: Mechanisms of Dysfunction in the Aging Vasculature and Role in Age-Related Disease. Circ Res 2018; 123(7):825-848. https://doi.org/10.1161/CIRCRESAHA.118.312563

FOX B, HARRIS RA: Oral antioxidants improve endothelial function in patients with cystic fibrosis. J Invest Med 61: $455,2013$. 
GOEDHART PT, KHALILZADA M, BEZEMER R, MERZA J, INCE C: Sidestream Dark Field (SDF) imaging: a novel stroboscopic LED ring-based imaging modality for clinical assessment of the microcirculation. Opt Express 15: 15101-15114, 2007. https://doi.org/10.1364/OE.15.015101

HADI ARH, CARR SC, SUWAIDI JA: Endothelial dysfunction: cardiovascular risk factors, therapy, and outcome. Vasc Health Risk Manag 1: 183-198, 2005.

HAMBURG NM, KEYES MJ, LARSON MG, VASAN RS, SCHNABEL R, PRYDE MM, MITCHELL GF, SHEFFY J, VITA JA, BENJAMIN EJ: Cross-sectional relations of digital vascular function to cardiovascular risk factors in the Framingham Heart Study. Circulation 117: 2467-2474, 2008. https://doi.org/10.1161/CIRCULATIONAHA.107.748574

HASHIMOTO R, KURATA T, SEKINE M, NAKANO K, OHNISHI T, HANEISHI H: Two-wavelength oximetry of tissue microcirculation based on sidestream dark-field imaging. J Biomed Opt 24: 1-8, 2018. https://doi.org/10.1117/1.JBO.24.3.031013

HECTOR A, GRIESE M, HARTL D: Oxidative stress in cystic fibrosis lung disease: an early event, but worth targeting. Eur Respir J 44: 17-19, 2014. https://doi.org/10.1183/09031936.00038114

HENNO P, MAUREY C, DANEL C, BONNETTE P, SOUILAMAS R, STERN M, DELCLAUX C, LÉVY M, ISRAËL-BIET D: Pulmonary vascular dysfunction in end-stage cystic fibrosis: role of NF-kappaB and endothelin-1. Eur Respir J 34: 1329-1337, 2009. https://doi.org/10.1183/09031936.00186908

HULL JH, GARROD R, HO TB, KNIGHT RK, COCKCROFT JR, SHALE DJ, BOLTON CE: Increased augmentation index in patients with cystic fibrosis. Eur Respir J 34: 1322-1328, 2009. https://doi.org/10.1183/09031936.00044009

HULL JH, GARROD R, HO TB, KNIGHT RK, COCKCROFT JR, SHALE DJ, BOLTON CE: Dynamic vascular changes following intravenous antibiotics in patients with cystic fibrosis. J Cyst Fibros 12: 125-129, 2013. https://doi.org/10.1016/j.jcf.2012.07.004

JEHLIČKA P, HUML M, SCHWARZ J, TREFIL L, KOBR J, SÝKORA J: Reactive Hyperaemia Index as a marker of endothelial dysfunction in children with Crohn's disease is significantly lower than healthy controls. Acta Paediatrica 103: 55-60, 2014. https://doi.org/10.1111/apa.12467

JOHANSSON PI, STENSBALLE J, RASMUSSEN LS, OSTROWSKI SR: A high admission syndecan-1 level, a marker of endothelial glycocalyx degradation, is associated with inflammation, protein C depletion, fibrinolysis, and increased mortality in trauma patients. Ann Surg 254: 194-200, 2011. https://doi.org/10.1097/SLA.0b013e318226113d

KELLY AS, MARLATT AL, STEINBERGER L, DENGEL DR: Younger age is associated with lower reactive hyperemic index but not lower flow-mediated dilation among children and adolescents. Atherosclerosis 234: 410-414, 2014. https://doi.org/10.1016/j.atherosclerosis.2014.03.031

KETTLE AJ, TURNER R, GANGELL CL, HARWOOD DT, KHALILOVA IS, CHAPMAN AL, WINTERBOURN CHC, SLY PD: Oxidation contributes to low glutathione in the airways of children with cystic fibrosis. Eur Respir J 44: 122-129, 2014. https://doi.org/10.1183/09031936.00170213

KITTNAR O: Selected sex related differences in pathophysiology of cardiovascular system. Physiol Res 69: 21-31, 2020. https://doi.org/10.33549/physiolres. 934068

KRAML P: The role of iron in the pathogenesis of atherosclerosis. Physiol Res 66: 55-67, 2017. https://doi.org/10.33549/physiolres.933589

MASOLA V, ZAZA G, ARDUINI A, ONISTO M, GAMBARO G: Endothelial glycocalyx as a regulator of fibrotic processes. Int J Mol Sci 22: 2996, 2021. https://doi.org/10.3390/ijms22062996

MASOPUSTOVÁ A, JEHLIČKA P, HUML M, VOTAVA T, TREFIL L, KRESLOVÁ M, SÝKORA J: Plethysmographic and biochemical markers in the diagnosis of endothelial dysfunction in pediatric acute lymphoblastic leukemia survivors-new applications. Physiol Res 67: 903-909, 2018a. https://doi.org/10.33549/physiolres.933754

MASOPUSTOVÁ A. Endothelial dysfunction in Children and Young Adults: A combined Diagnostic Approach of Plethysmographic and Biochemical Markers. In: Advances in Health and Disease. MASOPUSTOVÁ A, KRESLOVÁ M, SÝKORA J, JEHLIČKA P, TREFIL L, KOBR J (Eds.) 1st ed. New York: Nova Science Publishers, 2018b:189-202. 
MORRISON KM, DYAL L, CONNER W, HELDEN E, NEWKIRK L, YUSUF S, LONN E: Cardiovascular risk factors and non-invasive assessment of subclinical atherosclerosis in youth. Atherosclerosis 208: 501-505, 2010. https://doi.org/10.1016/j.atherosclerosis.2009.07.034

NIEUWDORP, M, MEUWESE MC, VINK H, HOEKSTRA JB, KASTELEIN JJ, STROES ES: The endothelial glycocalyx: a potential barrier between health and vascular disease. Curr Opin Lipidol 16: 507-511, 2005. https://doi.org/10.1097/01.mol.0000181325.08926.9c

NOWAK JK, WOJSYK-BANASZAK I, MĄDRY E, WYKRĘTOWICZ A, KRZYŻANOWSKA P, DRZYMAŁACZYŻ S, NOWICKA A, POGORZELSKI A, SAPIEJKA E, SKORUPA W, SZCZEPANIK M, LISOWSKA A, WALKOWIAK J: Increased soluble VCAM-1 and normal P-selectin in cystic fibrosis: a cross-sectional study. Lung 195: 445-453, 2017. https://doi.org/10.1007/s00408-017-0029-y

OLVEIRA G, OLVEIRA C, DORADO A, GARCÍA-FUENTES E, RUBIO E, TINAHONES F, SORIGUER F, MURRI M: Cellular and plasma oxidative stress biomarkers are raised in adults with bronchiectasis. Clin Nutr 32: 112-117, 2013. https://doi.org/10.1016/j.clnu.2012.06.002

OSIKA W, MONTGOMERY SM, DANGARDT F, WÄHRBORG P, GAN LM, TIDEMAN E, FRIBERG P: Anger, depression and anxiety associated with endothelial function in childhood and adolescence. Arch Dis Child 96: 38-43, 2011. https://doi.org/10.1136/adc.2008.152777

POORE S, BERRY B, EIDSON D, MCKIE KT, HARRIS RA: Evidence of vascular endothelial dysfunction in young patients with cystic fibrosis. Chest 143: 939-945, 2013. https://doi.org/10.1378/chest.12-1934

POORE TS, TAYLOR-COUSARB JL, ZEMANICK ET: Cardiovascular complications in cystic fibrosis: A review of the literature. J Cyst Fibros 14: 1569-1993, 2021. https://doi.org/10.1016/j.jcf.2021.04.016

REVERRI EJ, MORRISSEY BM, CROSS CE, STEINBERG FM: Inflammation, oxidative stress, and cardiovascular disease risk factors in adults with cystic fibrosis. Free Radic Biol Med 76: 261-277, 2014. https://doi.org/10.1016/j.freeradbiomed.2014.08.005

RODRIGUEZ-MIGUELEZ P, THOMAS J, SEIGLER N, CRANDALL R, MCKIE KT, FORSEEN C, HARRIS RA: Evidence of microvascular dysfunction in patients with cystic fibrosis. Am J Physiol Heart Circ Physiol 310: 1479-1485, 2016. https://doi.org/10.1152/ajpheart.00136.2016

ROSS R: Atherosclerosis--an inflammatory disease. $\quad \mathrm{N} \quad$ Engl $\quad \mathrm{J} \quad \mathrm{Med} \quad 340: \quad 115-126, \quad 1999$. https://doi.org/10.1056/NEJM199901143400207

SELAMET TIERNEY ES, NEWBURGER JW, GAUVREAU K, GEVA J, COOGAN E, COLAN SD, DE FERRANTI SD: Endothelial pulse amplitude testing: feasibility and reproducibility in adolescents. J Pediatr 154: 901-905, 2009. https://doi.org/10.1016/j.jpeds.2008.12.028

SLÍVA J, CHARALAMBOUS C, BULTAS J, KARETOVÁ D: A new strategy for the treatment of atherothrombosis inhibition of inflammation. Physiol Res 68: 17-30, 2019. https://doi.org/10.33549/physiolres.934327

TUCKER MA, FOX BM, SEIGLER N, RODRIGUEZ-MIGUELEZ P, LOONEY J, THOMAS J, MCKIE KT, FORSEEN C, DAVISON GW, HARRIS RA: Endothelial dysfunction in cystic fibrosis: role of oxidative stress. Oxid Med Cell Longev 2019: 1629638, 2019. https://doi.org/10.1155/2019/1629638

VÍTEK L: Bilirubin and atherosclerotic diseases. Physiol Res 66: 11-20, 2017. https://doi.org/10.33549/physiolres.933581

VRABLÍK M: Atherosclerosis - so well-known and still mysterious. Physiol Res 66: i-ii, 2017.

WIDLANSKY ME, GOCKE N, KEANEY JF JR, VITA JA: The clinical implications of endotehlial dysfunction. J Am Coll Cardiol 42: 1149-1160, 2003. https://doi.org/10.1016/S0735-1097(03)00994-X

YILMAZ O, AFSAR B, ORTIZ A, KANBAY M: The role of endothelial glycocalyx in health and disease. Clin Kidney J 12: 611-619, 2019. https://doi.org/10.1093/ckj/sfz042

YAMAOKA-TOJO M: Endothelial glycocalyx damage as a systemic inflammatory microvascular endotheliopathy in COVID-19. Biomed J 43: 399-413, 2020. https://doi.org/10.1016/j.bj.2020.08.007

YANG Y, HAEGER SM, SUFLITA MA, ZHANG F, DAILEY KL, COLBERT JF, FORD JA, PICON MA, STEARMAN RS, LIN L, LIU X, HAN X, LINHARDT RJ, SCHMIDT EP: Fibroblast growth factor signaling mediates pulmonary endothelial glycocalyx reconstitution. Am J Respir Cell Mol Biol 56: 727-737, 2017. https://doi.org/10.1165/rcmb.2016-03380C 